\title{
Efeito de fosfito de potássio e de fungicidas no controle da cercosporiose (Cercospora beticola) da beterraba
}

\author{
Leandro Luiz Marcuzzo ${ }^{1}$, Tatiana da Silva Duarte ${ }^{2}$, Antonio João Rosa Neto ${ }^{1}$, Felipe Hoffmann ${ }^{1}$
}

${ }^{1}$ Instituto Federal Catarinense - IFC/Campus Rio do Sul, CP 441, 89.163-356, Rio do Sul, SC; ${ }^{2}$ Universidade Federal do Rio Grande do Sul UFRGS, Faculdade de Agronomia, Departamento de horticultura e silvicultura, CP 15.100, 91540-000, Porto Alegre, RS.

Autor para correspondência: Leandro Luiz Marcuzzo (marcuzzo@ifc-riodosul.edu.br)

Data de chegada: 19/10/2015. Aceito para publicação em: 21/01/2016.

$10.1590 / 0100-5405 / 2135$

A principal doença da cultura da beterraba é a cercosporiose causada por Cercospora beticola. Os sintomas característicos da doença são manchas circulares com margem purpúrea e centro claro e à medida que evolui acaba ficando com tonalidade acinzentada. Após a necrose do tecido afetado a folha fica perfurada. $\mathrm{O}$ aumento das lesões e da área lesionada leva à senescência da folha e a uma diminuição da área foliar fotossintética, que conseqüente diminui a produtividade. A resistência genética esta entre os métodos de controle, porém, em trabalho realizado por Marcuzzo et al. (Horticultura brasileira, v.33, n.1, p.106-109, 2015) não verificaram resistência à cercoporiose entre os principais genótipos comercializados no Brasil. Mediante a isso, o controle químico através de fungicidas é a principal medida de controle da doença utilizada a campo pelo produtor, principalmente os de ação sistêmica (Filgueira, novo manual de olericultura: agrotecnologia moderna na produção e comercialização de hortaliças, 2007). Apesar de registrados no ministério da agricultura não se conhece a eficácia dos produtos que são utilizados em condição de campo. Atualmente o uso de indutores de resistência como fosfito de potássio tem proporcionado controle para diversas doenças e culturas (Cavalcanti et al. Indução de resistência em plantas a patógenos e insetos, 2005), mas não se conhece o efeito deste para a cercosporiose da beterraba. Mediante a esse aspecto, esse trabalho teve como objetivo avaliar o efeito de fosfito de potássio e também de sua mistura com fungicidas comerciais no controle da cercoporiose da beterraba. O experimento foi instalado na Epagri, Estação Experimental de Ituporanga (Região do Alto Vale do Itajaí, SC) em 2014/2015 (semeadura em 01/12/2014 e colheita em 19/03/2015) utilizando-se o híbrido Boro. O delineamento utilizado foi em blocos casualizados com quatro repetições e doze tratamentos constituídos na dose comercial de: azoxistrobina+difenoconazole (400 mL.ha $\left.{ }^{-1}\right)$; azoxistrobina (130 g. $\left.100 \mathrm{~L}^{-1}\right)$; oxicloreto de cobre+mancozebe $\left(200\right.$ g. $\left.100 \mathrm{~L}^{-1}\right)$; mancozebe $\left(3 \mathrm{~kg} \mathrm{ha}^{-1}\right)$; difenoconazole $\left(40 \mathrm{~mL} .100 \mathrm{~L}^{-1}\right)$; Tebuconazole (1 L.ha $\left.{ }^{-1}\right)$; fosfito de potássio $\left(200 \mathrm{~mL} .100 \mathrm{~L}^{-1}\right)+($ oxicloreto de cobre+mancozebe); fosfito de potássio+tebuconazole; fosfito de potássio+azoxistrobina; fosfito de potássio+mancozebe; fosfito de potássio e testemunha pulverizada com água.. A semeadura foi realizada manualmente, sendo que cada unidade experimental continha $2,25 \mathrm{~m}^{2}(1,5 \mathrm{~m} \times 1,5 \mathrm{~m})$, dividida em 5 linhas com espaçamento de $30 \mathrm{~cm}$ entre linhas e 10 $\mathrm{cm}$ entre plantas, contendo um total de 75 plantas. As aplicações dos fungicidas e água foram realizadas semanalmente a partir da semeadura através de pulverizador portátil de compressão prévia sob pressão contínua de $40 \mathrm{lbs} / \mathrm{pol}^{2}$ e vazão de 400 litros.ha ${ }^{-1}$. Semanalmente após a emergência foi avaliada a severidade da cercosporiose em dez plantas marcadas aleatoriamente dentro de cada repetição com auxílio de escala diagramática (May de Mio et al., Scientia agraria, n.1, p.331$337,2008)$. Os dados de severidade foram integralizados e calculados pela área abaixo da curva de progresso da doença (AACPD) através da

Tabela 1. Valores da área abaixo da curva do progresso da doença (AACPD), severidade final (\%), taxa de infecção ( $r$ ) e produtividade (Kg.ha $\left.{ }^{-1}\right)$ na avaliação de fungicidas com e sem fosfito de potássio no controle da cercosporiose da beterraba. Epagri/E.E Ituporanga 2014/2015

\begin{tabular}{lllll}
\hline Tratamentos & AACPD & Severidade final & r & Produtividade (Kg.ha $^{-1}$ ) \\
\hline Azoxistrobina+difenoconazole & $15,72 \mathrm{ab}$ & $0,68 \mathrm{c}$ & $0,05 \mathrm{~b}$ & $44.88 \mathrm{~ns}$ \\
Azoxistrobina & $13,74 \mathrm{ab}$ & $2,17 \mathrm{abc}$ & $0,09 \mathrm{ab}$ & 47.48 \\
Oxicloreto de cobre+mancozebe & $9,49 \mathrm{~b}$ & $1,18 \mathrm{bc}$ & $0,06 \mathrm{~b}$ & 47.14 \\
Mancozebe & $30,85 \mathrm{a}$ & $4,15 \mathrm{a}$ & $0,10 \mathrm{ab}$ & 49.74 \\
Difenoconazole & $16,95 \mathrm{ab}$ & $1,11 \mathrm{bc}$ & $\mathrm{b}$ & 43.87 \\
Tebuconazole & $7,38 \mathrm{~b}$ & $1,24 \mathrm{bc}$ & $0,06 \mathrm{ab}$ & 48.28 \\
Fosfito de potássio+(Ox. cobre+mancozebe) & $9,51 \mathrm{~b}$ & $1,19 \mathrm{bc}$ & $0,06 \mathrm{ab}$ & 53.42 \\
Fosfito de potássio+tebuconazole & $29,24 \mathrm{a}$ & $3,20 \mathrm{ab}$ & $0,12 \mathrm{a}$ & 43.51 \\
Fosfito de potássio+azoxistrobina & $21,29 \mathrm{ab}$ & $1,84 \mathrm{abc}$ & $0,08 \mathrm{ab}$ & 46.78 \\
Fosfito de potássio+mancozebe & $10,65 \mathrm{~b}$ & $2,00 \mathrm{abc}$ & $0,07 \mathrm{ab}$ & 45.90 \\
Fosfito de potássio & $9,65 \mathrm{~b}$ & $1,09 \mathrm{bc}$ & $0,08 \mathrm{ab}$ & 43.32 \\
Testemunha (água) & $30,10 \mathrm{a}$ & $3,88 \mathrm{a}$ & $0,10 \mathrm{ab}$ & 48.81 \\
\hline C.V (\%) & 40,72 & 47,72 & 28,34 & 17,19 \\
\hline
\end{tabular}

Médias seguidas de mesma letra não diferem pelo teste de Tukey 5\%; ns-não significativo; C.V-coeficiente de variação. 
fórmula: $\mathrm{AACPD}=\sum[(y 1+y 2) / 2] *(t 2-t 1)$, onde $y 1$ e $y 2$ que refere-se a duas avaliações sucessivas da intensidade da doença realizadas nos tempos $t 1$ e $t 2$, respectivamente (Campbell \& Madden, Introduction to plant disease epidemiology, 1990). Avaliou-se a taxa de infecção proposta por Vanderplank (Plant disease: epidemics and control, 1963). $\mathrm{Na}$ colheita, as plantas avaliadas foram pesadas e convertidas para produtividade em $\mathrm{kg} \cdot \mathrm{ha}^{-1}$. As médias obtidas da AACPD, severidade final $(\%)$, taxa de infecção $(r)$ e da produtividade $\left(\mathrm{kg} \cdot \mathrm{ha}^{-1}\right)$ foram submetidos à análise estatística pelo software SASM-Agri (Canteri et al., Revista brasileira de agrocomputação, v.1, n.1, p.18-24, 2001) para constatar o efeito dos tratamentos. Verificou-se que o tebuconazole apresentou menor valor integralizado $(7,38)$ na AACPD, mas não diferiu estatisticamente de oxicloreto de cobre+mancozeb $(9,49)$ (Tabela 1). O uso isolado de fosfito de potássio também não diferiu na AACPD em relação ao tebuconazole e também quando misturado com oxicloreto de cobre+mancozeb e mancozebe. O uso isolado de mancozebe e a mistura de fosfito de potássio com tebuconazole não apresentaram diferença de controle da doença quanto a AACPD e foi semelhante à testemunha (Tabela 1). Quanto à severidade final, mancozebe apresentou a maior severidade $(4,15 \%)$ e a menor severidade foi verificada com uso de azoxistrobina+difenoconazole $(0,68 \%)$ (Tabela 1$)$. O controle químico influencia diretamente na taxa de infecção (Zadoks \& Schein, Epidemiology and plant disease management, 1979) e nesse trabalho verificou-se que difenoconazole, oxicloreto de cobre+mancozeb e azoxistrobina+difenoconazole apresentaram estatisticamente a menor taxa de infecção, enquanto que fosfito de potássio+tebuconazole apresentou a maior taxa $(0,12)$ (Tabela 1$)$. Anesiadis et al. (Journal of Phytopathology, v.151, n.12, p.647-651, 2003) constataram que o uso de difeconazole apresentou resultados semelhantes a azoxistrobina no controle da doença em beterraba açucareira na Grécia, confirmando com os resultados desse trabalho. Secor et al. (Plant disease, v.94, n.11, p.1272-1782, 2010) descrevem que azoxistrobina, mancozebe e tebuconazole são fungicidas eficientes e comumente utilizados em Minessota e Dakota do Norte nos Estados Unidos da América para o controle da cercosporiose em beterraba açucareira. Felipini et al. (Tropical plant pathology, v.40, n.3, p.176-183, 2015) avaliando o efeito de acibenzolar-S-methyl como indutor de resistência verificou que a beterraba teve severidade de $1,3 \%$ quando aplicado em sete dias, coincidindo com os resultados aqui encontrados $(1,09 \%)$, comprovando também que o fosfito de potássio tem efeito de indução de resistência contra a cercoporiose na beterraba. A produtividade não foi significativa entre os tratamentos, provavelmente devido à baixa ocorrência da doença na testemunha $(3,88)$, porém o uso de fosfito de potássio + (oxicloreto de cobre + mancozebe) teve a maior produtividade (53.42 kg.ha-1) comparado aos demais tratamentos (Tabela 1), possivelmente devido o efeito de incremento de produção pelo efeito nutricional do fosfito de potássio. Mediante aos resultados obtidos para as condições de avaliação, o fungicida sistêmico tebuconazole e o preventivo oxicloreto de cobre+mancozebe foram superiores e o uso de fosfito de potássio isolado tem a mesma eficiência de controle dos fungicidas, podendo ser utilizado também em mistura com mancozebe ou mancozebe+oxicloreto de cobre no controle da cercoporiose da beterraba na região do Alto Vale do Itajaí, SC.

\section{Agradecimento}

Ao CNPq e à FAPESC (chamada pública do acordo de cooperação CNPq + FAPESC -Repensa) pelo apoio financeiro recebido para condução deste trabalho e pela concessão de bolsas ATP - B. 